\title{
Differences of tear film osmolarity between two time-points of the day in healthy subjects
}

\author{
Hugo Pena-Verdeal, Covadonga Vazquez-Sanchez, Jacobo Garcia- \\ Queiruga, Carlos Garcia-Resua \\ Department of Applied Physics (Area of Optometry), Universidade de Santiago de \\ Compostela, Santiago de Compostela, Spain
}

\begin{abstract}
Purpose: Tear film hyperosmolarity is considered one the core mechanism of the dry eye along with the tear film stability. Many tear physiological variables oscillate during the day. This study was designed to assess the differences in tear film osmolarity between morning and afternoon in a group of healthy subjects.

Material and methods: A total of 25 healthy subjects who fulfilled the study's inclusion criteria were enrolled for the study. Tear osmolarity was measured using the TearLab ${ }^{\mathrm{TM}}$ system in two separated sessions, at $9.30 \mathrm{am}$ and $6.30 \mathrm{pm}$. A paired t-test and a Bland-Altman test were used to assess the differences between sessions.

Results: Tear osmolarity (mean \pm SD) was $309.96 \pm 9.00$ and $296.48 \pm 12.98 \mathrm{mOsm} / \mathrm{l} \mathrm{at}$ $9.30 \mathrm{am}$ and $6.30 \mathrm{pm}$, respectively, being significantly lower at $6.30 \mathrm{pm}$ than at $9.30 \mathrm{am}$ (mean difference $\pm S D=13.48 \pm 8.69 \mathrm{mOsm} /$; ; paired t-test; $\mathrm{p}<0.001$ ).

Conclusions: Tear film osmolarity does appear to have some influence by the time of day in healthy patients.
\end{abstract}

Keywords: dry eye disease, osmolarity diurnal variations, tear film osmolarity, TearLab

\section{Introduction}

Dry eye disease (DED) has recently been redefined by the Dry Eye Workshop II (DEWS II) as a multifactorial disease of the ocular surface characterized by a loss of homeostasis of the tear film, and accompanied by ocular symptoms, in which tear film instability and hyperosmolarity, ocular surface inflammation and damage and neurosensory abnormalities play aetiological roles. ${ }^{1-4}$ Similar to the original DEWS report in $2007,,^{5-7}$ the DEWS II report reaffirmed that tear film instability and increased tear osmolarity are key mechanisms in DED, regardless of the underlying aetiology. ${ }^{4,8}$ The inclusion of "homeostasis" in the new definition emphasizes that DED is not caused by any single factor but rather a fine balance of many different systems working in concert. It has been proposed that on normal or healthy subjects the tear film osmolarity value is near to $300 \mathrm{mOsm} / \mathrm{l}$, while reaches to values up to 325 to $340 \mathrm{mOsm} / \mathrm{l}$ or

Correspondence: Hugo Pena-Verdeal,

E-mail: hugo.pena.verdeal@usc.es 
higher on abnormal or dry eye subjects..$^{9-11}$ Thus, osmolarity measurement has been proposed as the gold standard in the dry eye diagnosis, being an easy and useful way to capture in a single parameter the status of the tear film status. ${ }^{12}$

Many physiological tear film and ocular surface variables change along the day, such as the corneal sensitivity, the tear $\mathrm{pH}$ or the tear film volume in the meniscus. ${ }^{13-15}$ The possibility of diurnal variations in tear film parameter should be considered by the clinician, since the time of day tear film measurements are made can influence or be critical for a right diagnosis. A hallmark of DED is an unstable tear film, which is associated with variability in objective measures of sign and symptoms on this disease..$^{4,16,17}$ While repeated measurements over a period of time have been shown to be low and stable in normal subjects, DED subjects showed relatively elevated and unstable readings. ${ }^{18-20}$ Indeed, the variability of osmolarity should be considered as an indication of the loss of tear film homeostasis that occurs with $D E D,{ }^{21}$ being recommended as a feature that clinicians should specifically be looking at diagnosis. ${ }^{22}$ The aim of this study was to assess differences of tear film osmolarity between two time-points of the day, morning and afternoon, in a group of young healthy subjects.

\section{Material and methods}

\section{Sample}

A total of 25 participants ( 10 men, 15 women, mean age $21.5 \pm 2.72$ years), who fulfilled the study's inclusion established on a previous report, ${ }^{23}$ were recruited from students and subjects attending the Optometry Clinic of the Optometry Faculty (USC, Spain). Subjects were excluded if they had a history of the conjunctival, scleral or corneal disease, prior eye surgery, glaucoma, diabetes mellitus, a thyroid disorder or wore contact lenses. Qualifying subjects were also administered a battery of dry eye tests (OSDI and McMonnies questionnaires, Schirmer test, phenol red test, tear meniscus height [TMH] and corneal staining) to rule out DED. Cut-off criteria were set at a score $<13$ for OSDI, ${ }^{24}$ a score $<10$ for McMonnies, ${ }^{25}>14.5 \mathrm{~mm}$ for both the Schirmer I test without anaesthesia and phenol red test, ${ }^{26,27}$ a corneal staining grade $\leq 1$ on the Oxford Grading Scale ${ }^{28}$ and a central TMH without fluorescein $\geq 0.20 \mathrm{~mm} .{ }^{29,30}$ Subjects were excluded if they failed to fulfill more than two of these six inclusion criteria. ${ }^{23}$ No participant was under any type of medication or used artificial tears at the time of the study. The study protocol was adhered to the tenets of the Declaration of Helsinki and was approved by the Ethics Committee of the University of Santiago de Compostela. 


\section{Experimental procedure}

Tear film osmolarity was measured using the TearLab ${ }^{\mathrm{TM}}$ (TearLab, San Diego, CA, USA). ${ }^{31-35}$ During all protocols, the instrument and test cards used for both study parts were kept in the same humidity-and temperature-controlled room. ${ }^{19}$ Quality control electronic check cards provided by the manufacturer was performed daily to verify the correct status of the system according to the given specifications (if reading was $334 \pm 3$, the pen was working correctly). In all procedures, the same test card lot number was used.

Participants were seated with the chin tilted upward and eyes directed towards the ceiling. The first eye to be measured was randomly selected. The instrument probe (housing the disposable microchip) was then placed on the lower tear meniscus until a beep is emitted indicating the tear sample has been collected. Measurements are directly made on the tear meniscus using the probe, which takes up the sample through capillary action. Only a $0.05-\mu \mathrm{l}$ tear sample is needed. The TearLab converts the electrical impedance of the sample into osmolarity $(\mathrm{mOsm} / \mathrm{l})$, which is displayed on the device screen. Device measurement range goes from 275 to $400 \mathrm{mOsm} / \mathrm{l}$. Measurements were performed in two separate sessions, at 9.30 am and $6.30 \mathrm{pm} .{ }^{23}$ Only the right eye was examined because of induced excess tearing in the second eye and to avoid overstating the precision of statistical estimates. ${ }^{36}$ Throughout the study, laboratory conditions of temperature, light and humidity were kept constant (temperature $20-23^{\circ} \mathrm{C}$, humidity 50-60\%).

\section{Statistical analysis}

SPSS statistical software, v. 19.0 for Windows (SPSS Inc., Chicago, IL), was used for data analysis. Significance was set at a $p \leq 0.05$ for all the analyses. Previous to analysis, the normal distribution of the data was checked using the KolmogorovSmirnov test; osmolarity data for both sessions data showed a normal distribution (both $p \geq 0.153) ;{ }^{37}$ hence, parametric tests were used.

Bland-Altman procedures were used $^{38}$ to compare intra-day differences in osmolarity obtained in each patient's eye on both sessions. Those differences

Table 1. Descriptive statistics, differences (paired t-test) and $95 \% \mathrm{Cl}$ between measurements recorded in the two sessions

\begin{tabular}{|l|l|l|l|l|l|}
\hline Session & Mean \pm SD & \multirow{2}{*}{$\begin{array}{l}\text { Mean difference } \pm \\
\text { SD }\end{array}$} & $\boldsymbol{p}$ & \multicolumn{2}{|l|}{ 95\% LoA } \\
\cline { 1 - 3 } & & & Minimum & Maximum \\
\hline $9.30 \mathrm{am}$ & $309.96 \pm 9.00$ & \multirow{2}{*}{$13.48 \pm 8.69$} & 0.001 & -3.55 & +30.51 \\
\hline $6.30 \mathrm{pm}$ & $296.48 \pm 12.98$ & & & & \\
\hline
\end{tabular}

All data expressed on $\mathrm{mOsm} / \mathrm{l} . n=25$

95\% Cl: 95\% confidence interval; 95\% LoA: 95\% limits of agreement; SD: standard deviation 


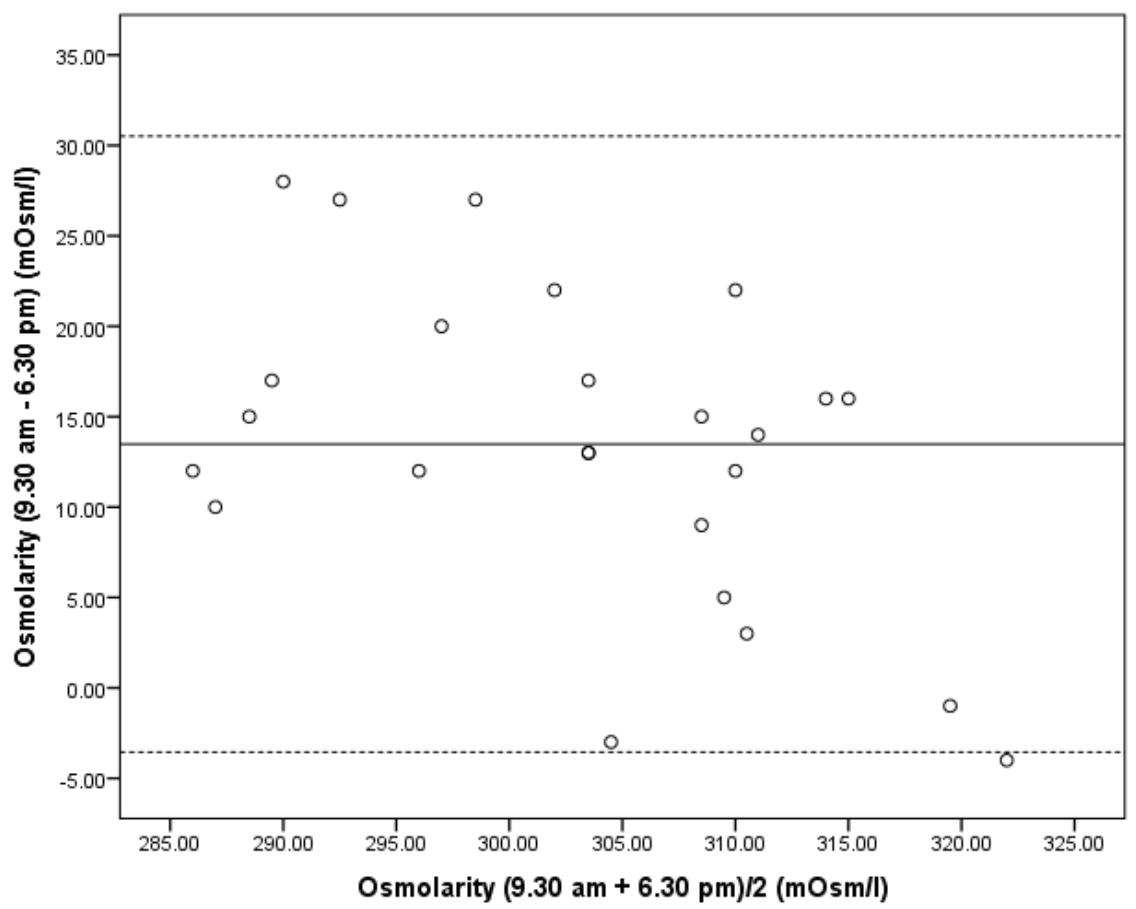

Fig. 1. Mean versus differences between the values obtained in the two sessions $(9.30 \mathrm{am}$ vs. $6.30 \mathrm{pm}$ ). The solid line indicates mean difference and dashed lines indicate the $95 \%$ LoA (Mean difference $\pm 1.96 \times$ SD differences). $S D=$ standard deviation. $\mathrm{n}=25$.

between both osmolarity measurement sessions were assessed using a paired $t$-test for related samples. Also, $95 \%$ limits of agreements (LoA) were calculated (mean difference $\pm 1.96 \times$ SD differences). In addition, a Bland-Altman plot representing averages versus differences was generated.

\section{Results}

Tear osmolarity (mean \pm SD) was $309.96 \pm 9.00 \mathrm{mOsm} / \mathrm{l}$ (values from 292 to 323) and $296.48 \pm 12.98 \mathrm{mOsm} / \mathrm{l}$ (values from 276 to 324) at $9.30 \mathrm{am}$ and $6.30 \mathrm{pm}$, respectively (Table 1). Results were significantly lower at $6.30 \mathrm{pm}$ than at $9.30 \mathrm{am}$ (paired $t$-test; $p<0.001$ ), indicating better tear film quality in the afternoon than in the morning on healthy subjects (Table 1).

Figure 1 provides a Bland-Altman plot of means against the differences between the osmolarity values obtained in each time-point. As could be seen, dots were spread and there a was wide bias according to the $95 \%$ confidence 
interval, showing high differences between the osmolarity values obtained in both morning and afternoon sessions.

\section{Discussion}

Diurnal variations in tear film variables have not been clearly established yet. The present findings indicate that tear film osmolarity does appear to be influenced by the time of day in healthy subjects: osmolarity readings indicated an improvement (lower osmolarity) in the afternoon (Fig. 1). As in previous reports, ${ }^{39,40}$ two time-points were used $(9.30 \mathrm{am}-6.30 \mathrm{pm})$, which represent the start and the end of a normal work timetable in Spain. ${ }^{40}$ In addition, it is important to note that the inclusion criterion for the present study was strict in order to use only really healthy patients.

Tear osmolarity is considered a global indicator of the DED.9-11,41,42 Elevated tear osmolarity induces apoptosis, serve as a pro-inflammatory stress and reduce the ability of mucin-like molecules to lubricate the ocular surface, which can permanently damage the ocular surface. ${ }^{41,43,44}$ It was reported that osmolarity is the single best marker of disease severity as an objective numerical measure for diagnosing, grading severity and managing treatment of DED. ${ }^{12,45}$ However, to date, there is still controversy over the best cut-off for osmolarity between normal and DED subjects. Most studies have examined the threshold for DED diagnosis, and were recommended values that vary from 308 to $320 \mathrm{mOsm} / 1 .{ }^{9-11,45}$ Using a cut-off of $312 \mathrm{mOsm} / \mathrm{l}$, tear osmolarity have a $72.8 \%$ sensitivity and $92.0 \%$ specificity in separating DED from normal eyes. ${ }^{9,45,46}$ While in the present study, a battery of specific dry eye diagnostic test was made as an inclusion criteria (OSDI, McMonnies, Schirmer, phenol red test, TMH and corneal staining). ${ }^{24-30}$ It is important to note that the mean osmolarity in the first session was near to this cut-off criteria value (mean $\pm \mathrm{SD}=309.96 \pm 9.00 \mathrm{mOsm} / \mathrm{l}$ ). On the other hand, normal eyes tend to vary by $\pm 7 \mathrm{mOsm} / \mathrm{l}$, whereas DED can vary $\geq 11 \mathrm{mOsm} / \mathrm{l}$ between eyes or and tests but generally a difference of $\geq 8 \mathrm{mOsm} / \mathrm{l}$ between eyes indicates tear film instability. ${ }^{4,9,16}$ In the present study, a mean difference \pm SD between morning and afternoon of $13.48 \pm 8.69$ was found, higher than those diagnostic values. One reported reason for variability in tear osmolarity threshold values is tear film instability, a hallmark characteristic of the disease. ${ }^{19,16}$ Indeed, the variability of osmolarity or increasing variation with increasing value is a statistical characteristic called heteroscedasticity and might be considered as a clinical indication of the loss of tear film homeostasis that occurs with dry eye. ${ }^{4,16,19,21,45}$ It has been reported that consecutive measurements of the tear film osmolarity in short periods of time showed a lower variability, contrary to dry eye patients. ${ }^{18,20}$ Tears of individuals with DED demonstrated increasing variation due to a combination of chaotic or incomplete mixing between blinks and spatially variable tear 
film break-up, leading to a stochastically increased evaporation rate. ${ }^{4,19}$

In addition to the cut-off limitation or differences between measurements, diurnal variations of that parameter should be assessed and established in order to minimize possible diagnosis misleading. Previous studies have also used the TearLab osmometer to assess the osmolarity diurnal variation in healthy patients. ${ }^{31-35}$ Some of those studies also reported no variations on tear film osmolarity along the day, ${ }^{31,34,35}$ while other shows variations in some points of the day. ${ }^{33}$ The same results were found in studies where osmometers based on freezing point depression were used, where variation ${ }^{47,48}$ and no variation ${ }^{40,49}$ was found between osmolarity measured at some different points of the day in healthy patients. Despite the little variations found in some measurement points on these studies, all of them concluded that osmolarity has a near to stable profile along the day in healthy subjects. In addition, although there is some controversy over diurnal tear film osmolarity, this variable has been observed to differ between healthy individuals and those pathological. ${ }^{33,35}$ Also, as eye closure during sleep generates a hypoosmotic environment due to the reduction in tear film evaporation, production, and drainage, it has been hypothesized by previous authors that osmolarity is in its lower values upon eyelid opening. ${ }^{37}$ Then, in the afternoon as the eye responds to the relative variations in the surrounding conditions that could enhance the evaporation process, ${ }^{51}$ osmolarity rises to normal values. ${ }^{31-35}$ Patients have reported that symptoms worsened over the day within 2 hours of getting up in the morning and at the end of the day, suggesting an environmentor task-related aetiology for dry eye symptoms. ${ }^{52}$

These differences between studies, both the daily variation and the relationship between healthy and pathological subjects, may reach from different error sources. The first one is the different criteria to choose the session day-time, with a wide range of day points from $6.00 \mathrm{am}^{49}$ to $7.00 \mathrm{pm}^{40}$ The second could be the different devices or principles used in the different studies, while some studies have been reported a poor correlation between different principle osmometers. ${ }^{53,54}$ Finally, the last source of error may be the different number of subjects in the studied groups (very small in some cases), ${ }^{55}$ or the variations between age, sex or symptomatology. A larger study population, both healthy and pathological, may be required to detect a true daily osmolarity pattern and the differences between the tear osmolarity of dry eye subjects and that of healthy individuals.

In summary, while the osmolarity general profile follows a near to stable pattern along the day, tear film osmolarity does appear to be influenced by the time of day in healthy patients. 


\section{Acknowledgements}

This study was funded by the Spanish Ministry of Science and Education and the Institute of Health Carlos III (ISCIII) through research project PI10/01098.

\section{References}

1. Bron AJ, de Paiva CS, Chauhan SK, et al. TFOS DEWS II pathophysiology report. Ocul Surf. 2017;15:438-510.

2. Craig JP, Nichols KK, Akpek EK, et al. TFOS DEWS II definition and classification report. Ocul Surf. 2017;15:276-283.

3. Stapleton F, Alves M, Bunya VY, et al. TFOS DEWS II epidemiology report. Ocul Surf. 2017;15:334-365.

4. Wolffsohn JS, Arita R, Chalmers R, et al. TFOS DEWS II diagnostic methodology report. Ocul Surf. 2017; 15:539-574.

5. The definition and classification of dry eye disease: report of the Definition and Classification Subcommittee of the International Dry Eye WorkShop. Ocul Surf. 2007;5:75-92.

6. Methodologies to diagnose and monitor dry eye disease: report of the Diagnostic Methodology Subcommittee of the International Dry Eye WorkShop. Ocul Surf. 2007;5:108-152.

7. Research in dry eye: report of the Research Subcommittee of the International Dry Eye WorkShop. Ocul Surf. 2007;5:179-193.

8. Nelson JD, Craig JP, Akpek EK, et al. TFOS DEWS II introduction. Ocul Surf. 2017;15:269-275.

9. Jacobi C, Jacobi A, Kruse FE, Cursiefen C. Tear film osmolarity measurements in dry eye disease using electrical impedance technology. Cornea. 2011;30:1289-1292.

10. Messmer EM, Bulgen M, Kampik A. Hyperosmolarity of the tear film in dry eye syndrome. Dev Ophthalmol. 2010;45:129-138.

11. Tomlinson A, Khanal S, Ramaesh K, Diaper C, McFadyen A. Tear film osmolarity: determination of a referent for dry eye diagnosis. Invest Ophthalmol Vis Sci. 2006;47:4309-4315.

12. Muselier-Mathieu A, Bron AM, Mathieu B, et al. Ocular surface assessment in soft contact lens wearers; the contribution of tear osmolarity among other tests. Acta Ophthalmol. 2014;92:364-369.

13. Carney LG, Hill RM. Human tear pH. Diurnal variations. Arch Ophthalmol. 1976;94:821-824.

14. du Toit R, Vega JA, Fonn D, Simpson T. Diurnal variation of corneal sensitivity and thickness. Cornea. 2003;22:205-209.

15. Shen M, Wang J, Tao A, et al. Diurnal variation of upper and lower tear menisci. Am J Ophthalmol. 2008;145:801-806.

16. Lemp MA, Bron AJ, Baudouin C, et al. Tear osmolarity in the diagnosis and management of dry eye disease. Am J Ophthalmol. 2011;151:792-798 e791.

17. Urzua CA, Vasquez DH, Huidobro A, Hernandez H, Alfaro J. Randomized double-blind clinical trial of autologous serum versus artificial tears in dry eye syndrome. Curr Eye Res. 2012;37:684-688.

18. Gokhale M, Stahl U, Jalbert I. In situ osmometry: validation and effect of sample collection technique. Optom Vis Sci. 2013;90:359-365.

19. Keech A, Senchyna M, Jones L. Impact of time between collection and collection method on human tear fluid osmolarity. Curr Eye Res. 2013;38:428-436.

20. Nolfi J, Caffery B. Randomized comparison of in vivo performance of two point-of-care tear film osmometers. Clin Ophthalmol. 2017;11:945-950.

21. Sullivan B. Challenges in using signs and symptoms to evaluate new biomarkers of dry eye disease. Ocul Surf. 2014;12:2-9.

22. Sullivan BD, Whitmer D, Nichols KK, et al. An objective approach to dry eye disease severity. Invest Ophthalmol Vis Sci. 2010;51:6125-6130. 
23. Pena-Verdeal H, Garcia-Resua C, Ramos L, Yebra-Pimentel E, Giraldez MJ. Diurnal variations in tear film break-up time determined in healthy subjects by software-assisted interpretation of tear film video recordings. Clin Exp Optom. 2016;99:142-148.

24. Miller KL, Walt JG, Mink DR, et al. Minimal clinically important difference for the ocular surface disease index. Arch Ophthalmol. 2010;128:94-101.

25. Glasson MJ, Stapleton F, Keay L, Sweeney D, Willcox MD. Differences in clinical parameters and tear film of tolerant and intolerant contact lens wearers. Invest Ophthalmol Vis Sci. 2003;44:5116-5124.

26. Nichols KK, Mitchell GL, Zadnik K. The repeatability of clinical measurements of dry eye. Cornea. 2004;23:272-285.

27. Nichols KK, Nichols JJ, Mitchell GL. The lack of association between signs and symptoms in patients with dry eye disease. Cornea. 2004;23:762-770.

28. Bron AJ, Evans VE, Smith JA. Grading of corneal and conjunctival staining in the context of other dry eye tests. Cornea. 2003;22:640-650.

29. Garcia-Resua C, Santodomingo-Rubido J, Lira M, Giraldez MJ, Vilar EY. Clinical assessment of the lower tear meniscus height. Ophthalmic Physiol Opt. 2009;29:487-496.

30. Johnson ME, Murphy PJ. The agreement and repeatability of tear meniscus height measurement methods. Optom Vis Sci. 2005;82:1030-1037.

31. Aslan Bayhan S, Bayhan HA, Muhafiz E, Bekdemir S, Gurdal C. Effects of osmoprotective eye drops on tear osmolarity in contact lens wearers. Can J Ophthalmol. 2015;50:283-289.

32. Dimit R, Miller W, Leach N, Bergmanson J. Comparison of morning and afternoon osmolarity in silicone hydrogel wearers and non-contact lens wearers. Invest Ophthalmol Vis Sci. 2011;52:6538.

33. Li M, Du C, Zhu D, Shen M, Cui L, Wang J. Daytime variations of tear osmolarity and tear meniscus volume. Eye Contact Lens. 2012;38:282-287.

34. Oncel BA, Pinarci E, Akova YA. Diurnal variation of the tear osmolarity in normal subjects measured by a new microchip system. Eur J Ophthalmol. 2012;22 Suppl 7:S1-S4.

35. Yiğit U, Evcimen Y, Kırık F, Ağaçhan A. Daytime variations of tear osmolarity measurement in dry eyes patients (article in turkish). Turk J Ophthalmol 2013;43:437-441.

36. Armstrong RA, Davies LN, Dunne MC, Gilmartin B. Statistical guidelines for clinical studies of human vision. Ophthalmic Physiol Opt. 2011;31:123-136.

37. Bland JM, Altman DG. Statistical methods for assessing agreement between two methods of clinical measurement. Lancet. 1986;1:307-310.

38. Farris RL, Stuchell RN, Mandel ID. Tear osmolarity variation in the dry eye. Trans Am Ophthalmol Soc. 1986;84:250-268.

39. Garcia N, Teson M, Enriquez-de-Salamanca A, et al. Basal values, intra-day and inter-day variations in tear film osmolarity and tear fluorescein clearance. Curr Eye Res. 2014;39:673-679.

40. Liu H, Begley C, Chen M, et al. A link between tear instability and hyperosmolarity in dry eye. Invest Ophthalmol Vis Sci. 2009;50:3671-3679.

41. Stahl U, Willcox M, Stapleton F. Osmolality and tear film dynamics. Clin Exp Optom. 2012;95:3-11.

42. Luo L, Li DQ, Pflugfelder SC. Hyperosmolarity-induced apoptosis in human corneal epithelial cells is mediated by cytochrome $c$ and MAPK pathways. Cornea. 2007;26:452-460.

43. Sullivan BD, Crews LA, Messmer EM, et al. Correlations between commonly used objective signs and symptoms for the diagnosis of dry eye disease: clinical implications. Acta Ophthalmol. 2014;92:161-166.

44. Potvin R, Makari S, Rapuano CJ. Tear film osmolarity and dry eye disease: a review of the literature. Clin Ophthalmol. 2015;9:2039-2047.

45. Ray WA, O'Day DM. Statistical analysis of multi-eye data in ophthalmic research. Invest Ophthalmol Vis Sci. 1985;26:1186-1188. 
46. Versura P, Profazio V, Campos EC. Performance of tear osmolarity compared to previous diagnostic tests for dry eye diseases. Curr Eye Res. 2010;35:553-564.

47. Benjamin WJ, Hill RM. Human tears: osmotic characteristics. Invest Ophthalmol Vis Sci. 1983;24:1624-1626.

48. Dalton $\mathrm{K}$, Jones $\mathrm{L}$. The performance of a novel nanolitre osmometer to investigate diurnal tear film osmolality. Optom Vis Sci 2005; 82. E-abstract 0557070.

49. Lee YB, Koh JW, Hyon JY, Wee WR, Kim JJ, Shin YJ. Sleep deprivation reduces tear secretion and impairs the tear film. Invest Ophthalmol Vis Sci. 2014;55:3525-3531.

50. Niimi J, Tan B, Chang J, et al. Diurnal pattern of tear osmolarity and its relationship to corneal thickness and deswelling. Cornea. 2013;32:1305-1310.

51. Himebaugh NL, Begley CG, Bradley A, Wilkinson JA. Blinking and tear break-up during four visual tasks. Optom Vis Sci. 2009;86: E106-E114.

52. Torricelli AA, Novaes P, Matsuda M, et al. Correlation between signs and symptoms of ocular surface dysfunction and tear osmolarity with ambient levels of air pollution in a large metropolitan area. Cornea. 2013;32:e11-e15.

53. Garcia N, Melvi G, Pinto-Fraga J, Calonge M, Maldonado MJ, Gonzalez-Garcia MJ. Lack of agreement among electrical impedance and freezing-point osmometers. Optom Vis Sci. 2016;93:482-487.

54. Pena-Verdeal H, Garcia-Resua C, Minones M, Giraldez MJ, Yebra-Pimentel E. Accuracy of a freezing point depression technique osmometer. Optom Vis Sci. 2015;92:e273-e283.

55. Benjamin WJ, Hill RM. Tear osmotic differences across the ocular surface. Graefes Arch Clin Exp Ophthalmol. 1986;224:583-586. 